\title{
Duobinary modulation/predistortion techniques effects on high bit rate radio over fiber systems
}

\author{
Mahmoud M. A. Eid ${ }^{1}$, Ashraf S. Seliem², Ahmed Nabih Zaki Rashed ${ }^{3}$, Abd El-Naser A. Mohammed ${ }^{4}$, \\ Mohamed Yassin $\mathrm{Ali}^{5}$, Shaimaa S. Abaza \\ ${ }^{1}$ Department of Electrical Engineering, College of Engineering, Taif University, Kingdom of Saudi Arabia \\ ${ }^{3,4}$ Electronics and Electrical Communications Engineering Department, Faculty of Electronic Engineering, Menoufia \\ University, Menouf, Egypt \\ ${ }^{2,5,6}$ Benha Faculty of Engineering, Benha University, Benha, Egypt
}

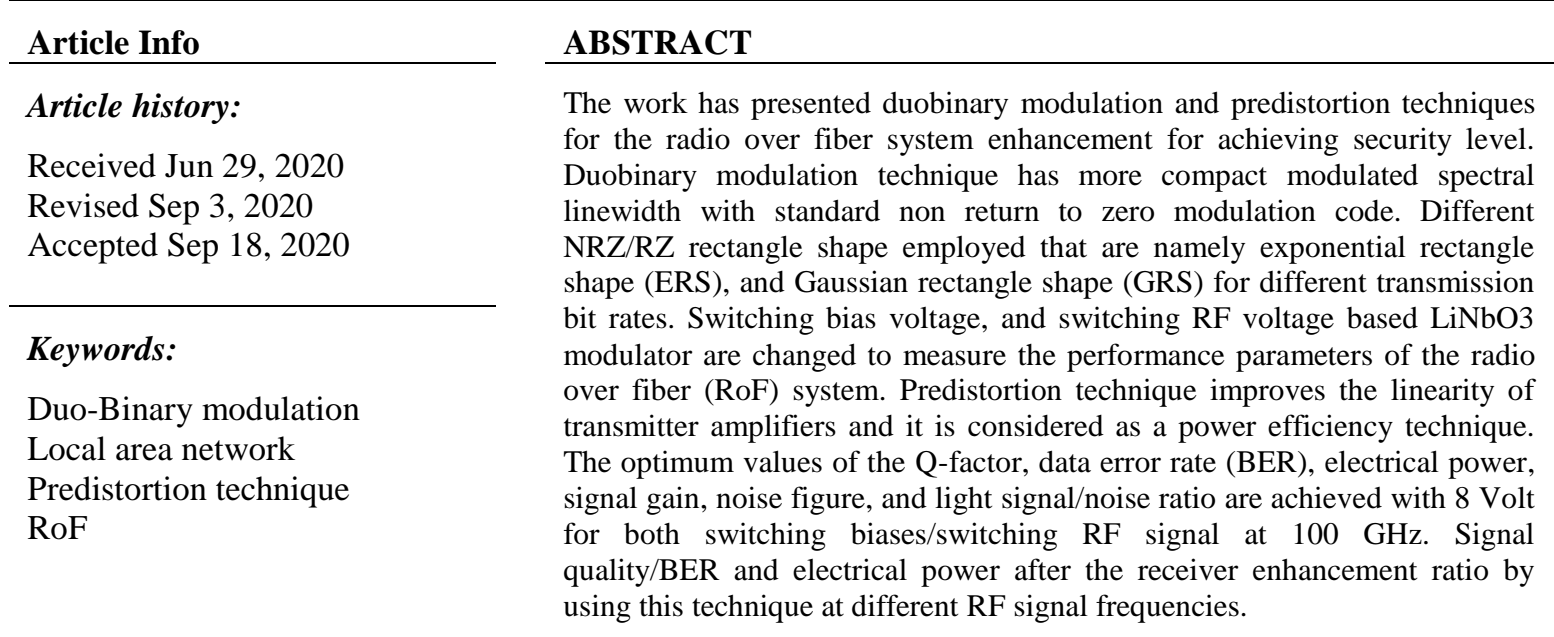

This is an open access article under the CC BY-SA license.

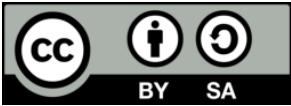

Corresponding Author:

Ahmed Nabih Zaki Rashed

Faculty of Electronic Engineering, Menoufia University

Menouf 32951, Egypt

E-mail: ahmed_733@yahoo.com

\section{INTRODUCTION}

They presented the RoF network model with the investigation of Q-factor, BER and eye-opening with optic fiber length, operating signal wavelength, and bit rate. The radio frequency signal is $10 \mathrm{GHz}$ with a data rate of up to $3 \mathrm{~Gb} / \mathrm{s}$ and is used in this model through fiber length up to $50 \mathrm{~km}$. This study shows that the RZ modulation code is better than the NRZ modulation code in the high power regime [1, 2, 3-9]. They clarified the simulation modeling of RoF for home network applications using different line coding. Performance parameters evaluation is summarized such as Q-factor, BER, eye height, and threshold value with respect to transmission bit rate and fiber cable length under different line coding schemes [3, 10-15].

Different electrical encoding methods and different optical modulation schemes are analyzed. Different wavelength division multiplexing, optical add/drop multiplexers are performed with the optimization of fiber cable length. The signal spectrum for both base stations is measured with the testing of the Q-factor and BER analyzer. As well as 8 channels are multiplexed and routed using wavelength selective optical add/drop multiplexer which is used as fiber Bragg grating filter [4, 5, 16-20]. Refs. [5, 6, 21-24] presented the filtration techniques that are employed for amplitude noise reduction based millimeter RoF 
communication [7, 8, 25-28]. The max quality factor and min data error rate are tested for different optical receivers (PIN, and APD photodetectors) with different types of noise (shot noise, and thermal noise). RoF systems is stimulated based on NRZ coding for a bit rate of $2.5 \mathrm{~Gb} / \mathrm{s}$ [29-37].

\section{MODEL DESCRIPTION AND RESEARCH METHOD}

We have developed the previous work in Ref. [6] to enhance radio over fiber-based local area communication network. By creating non return to zero duobinary signal code using a precoder and a duobinary pulse generator, so the duobinary signal can be generated. Pseudo random bit sequence generator to generate a random stream of bits. This stream is encoded in the configuration of return to zero code. The encoded signal can be directed to distortion generator which treats the signal nonlinearity. The generator derived the first $\mathrm{LiNbO}_{3}$ Mach Zehnder modulator and then concatenates this modulator with the second modulator driven by an electrical sinusoidal signal that has a clock frequency equal to the transmission data rate of $100 \mathrm{GHz}$. For the high-speed data transmission system, the clock frequency defines the transmission limit within the range of $10 \mathrm{GHz}$ to $250 \mathrm{GHz}$. The duobinary used a dedicated precoder at the transmitter that makes the receiver can use direct detection mechanism. The signal is directed from modulator to EDFA amplifier for amplification then into the single-mode fiber which its length of $20 \mathrm{~km}$. The routed signal from single-mode fiber cable is traveled to APD photodetector to convert the light signal to an electrical signal. The converted signal is treated from ripples through low pass Bessel filter and the Q factor and min BER are tested by bit error rate analyzer.

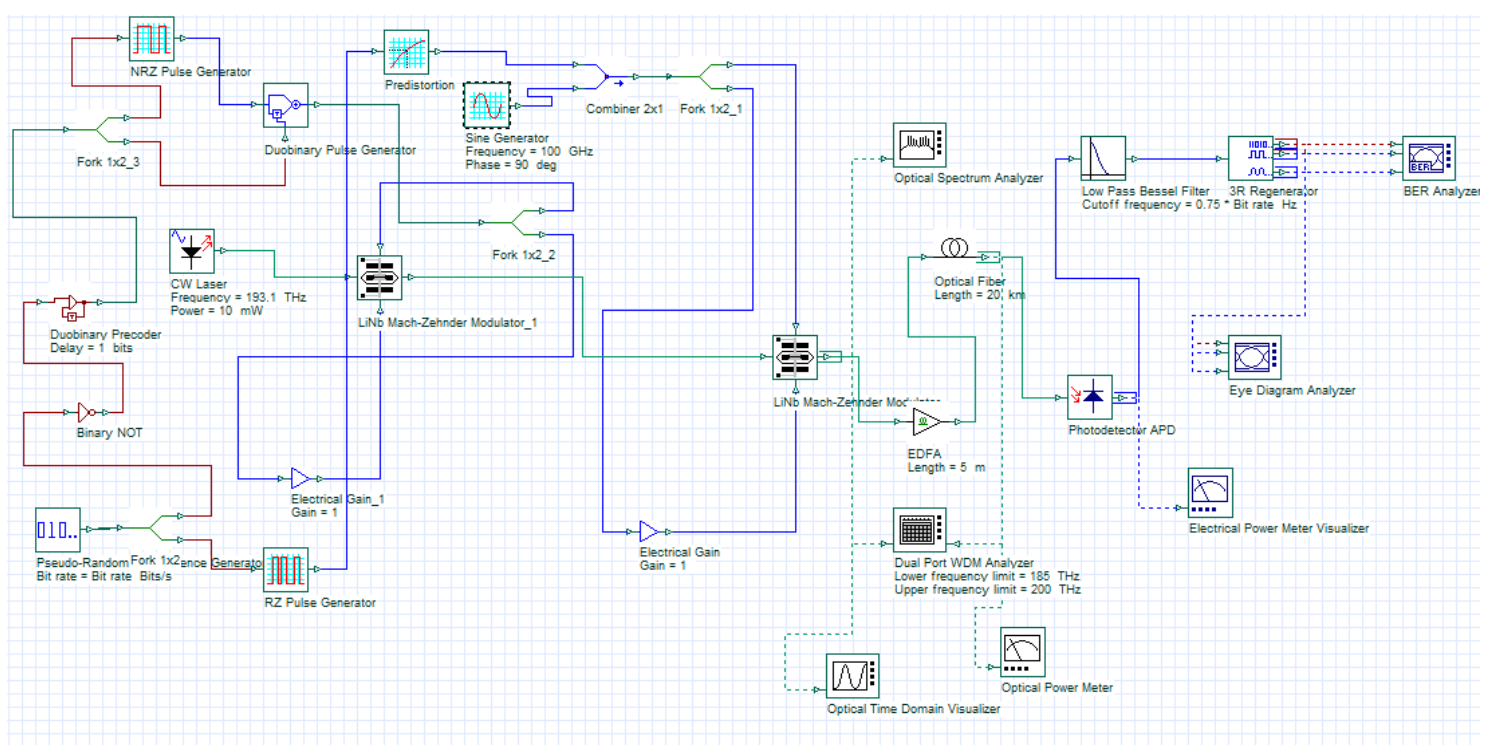

Figure 1. Schematic view of duobinary radio over fiber simulation modeling

There are many measurements after modulator and single-mode fiber cable to measure the RoF system operation performance. Dual-port WDM analyzer is used to measure the signal gain, noise figure, and optical signal to noise ratio. The optical power meter measures optical power into the fiber cable. The optical spectrum analyzer measures the modulated power on the vertical scale and the operating signal wavelength on the horizontal scale. As well as optical time-domain visualizer measures the modulated power with a bit time. Both BER analyzer and eye diagram analyzer to test the maxi. Q-factor and min. bit error rate at the receiver side.

\section{PERFORMANCE ANALYSIS WITH DISCUSSIONS}

Stimulated the duo-binary modulation and predistortion techniques are analyzed for the enhancement of radio over fiber communication systems for local area network applications with different transmission bit rates. Switching bias voltage and switching RF voltage are changed to reach the optimum value in order to achieve maximum quality factor enhancement and BER reduction in addition to the enhancement of electrical received power. The deduced figures are assured the obtained results: 
Figures 2 and 3 show the relation between max Q-factor and min bit error rate in relation to different NRZ/RZ rectangle shape. It is observed that the NRZ/RZ (ERS) configuration has presented maxi. Q-factor and min. BER that NRZ/RZ (GRS) configuration at $10 \mathrm{~Gb} / \mathrm{s}$, while NRZ/RZ (GRS) configuration has presented max. Q-factor and min. BER than NRZ/RZ (ERS) configuration at $40 \mathrm{~Gb} / \mathrm{s}$. The max. Q factor is 5.8 for the NRZ/RZ (ERS) configuration with $40 \mathrm{~Gb} / \mathrm{s}, 6.5$ for the NRZ/RZ (GRS) configuration with the same bit rate. The max. Q factor is 8.654 for the NRZ/RZ (ERS) configuration with $10 \mathrm{~Gb} / \mathrm{s}, 8.2435$ for the NRZ/RZ (GRS) configuration with the same bit rate. The min. BER is $1.5 \times 10^{-10}$ for NRZ/RZ (ERS) configuration with $40 \mathrm{~Gb} / \mathrm{s}, 0.9 \times 10^{-10}$ for the NRZ/RZ (GRS) configuration with the same bit rate. The min. BER is $13.5 \times 10^{-12}$ for the NRZ/RZ (ERS) configuration with $10 \mathrm{~Gb} / \mathrm{s}, 6.5 \times 10^{-12}$ for the NRZ/RZ (GRS) configuration with the same data rate.

Figure 4 indicates that the variations of electrical power after APD with different NRZ/RZ rectangle shape at various bit rates. The NRZ/RZ (GRS) configuration has presented larger electrical power at the receiver in compared with NRZ/RZ (ERS) configuration. The received power is $5.5 \mathrm{~mW}$ for the NRZ/RZ (ERS) configuration with $40 \mathrm{~Gb} / \mathrm{s}, 6.3 \mathrm{~mW}$ for the NRZ/RZ (GRS) configuration with the same bit rate. The received power is $18.654 \mathrm{~mW}$ for the NRZ/RZ (ERS) configuration with $10 \mathrm{~Gb} / \mathrm{s}, 19.2 \mathrm{~mW}$ for the NRZ/RZ (GRS) configuration with the same bit rate. Figure 5 demonstrates that the maximum Q-factor in relation to RF signal frequency with/without predistortion technique. It is inferred that the important role of predistortion technique in upgrading signal quality factor. The max. Q Factor is 8 with predistortion, 2.2 without predistortion at $10 \mathrm{~Gb} / \mathrm{s}$. The max. Q Factor is 5.5 with predistortion, 2.8 without predistortion at 40 $\mathrm{Gb} / \mathrm{s}$. The max. Q Factor is 7.8 with predistortion, 2.1 without predistortion at $100 \mathrm{~Gb} / \mathrm{s}$. The max. Q Factor is 8.354 with predistortion, 2.02 without predistortion at $160 \mathrm{~Gb} / \mathrm{s}$. The max. Q Factor is 7.354 with predistortion, 2.01 without predistortion at $250 \mathrm{~Gb} / \mathrm{s}$. Figures 6 and 7 show max. Q-factor variations with switching bias voltage and switching RF voltage. It is indicated that the optimum value of the maximum Qfactor is achieved at 8 Volt for both switching cases of the modulator. As shown in Figure 6, the max. Q factor is 2.1 at $4 \mathrm{~V}$ switching bias voltage. The max. Q factor is 14.8 at $8 \mathrm{~V}$ switching bias voltage. The max. $\mathrm{Q}$ factor is 5 at $12 \mathrm{~V}$ switching bias voltage. The max. $\mathrm{Q}$ factor is 4 at $16 \mathrm{~V}$ switching bias voltage. the max. $\mathrm{Q}$ factor is 3 at $20 \mathrm{~V}$ switching bias voltage. As shown in Figure 7, the max. Q factor is 2.225 at $4 \mathrm{~V}$ switching RF voltage. The max. Q factor is 2.775 at $8 \mathrm{~V}$ switching RF voltage. The max. Q factor is 2.7 at 12 $\mathrm{V}$ switching RF voltage. The max. Q factor is 2.654 at $16 \mathrm{~V}$ switching RF voltage. the max. Q factor is 2.554 at $20 \mathrm{~V}$ switching $\mathrm{RF}$ voltage.

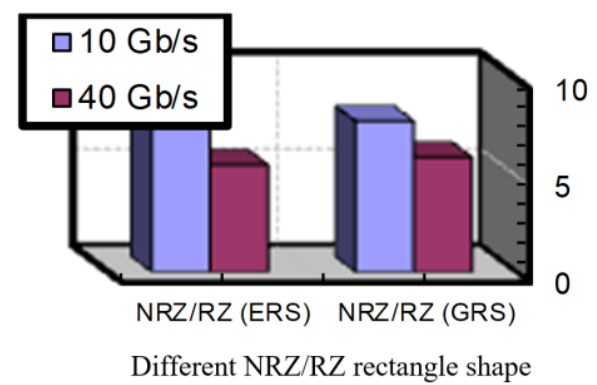

Figure 2. Variations of max Q-factor with overall system bit-rate based on different NRZ/RZ rectangle shape

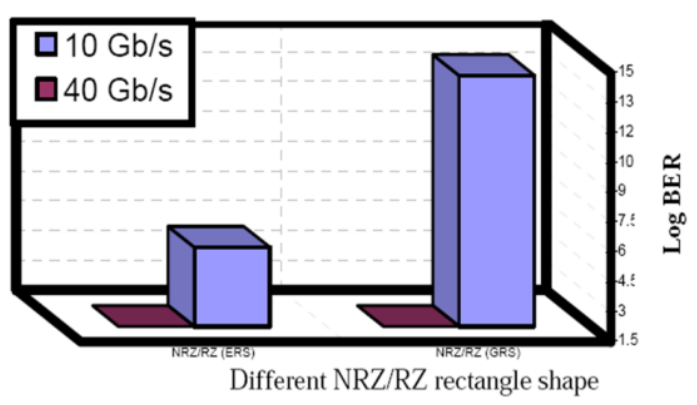

Figure 3. Min. data error rate variations versus overall system bit-rate based on different NRZ/RZ rectangle shape

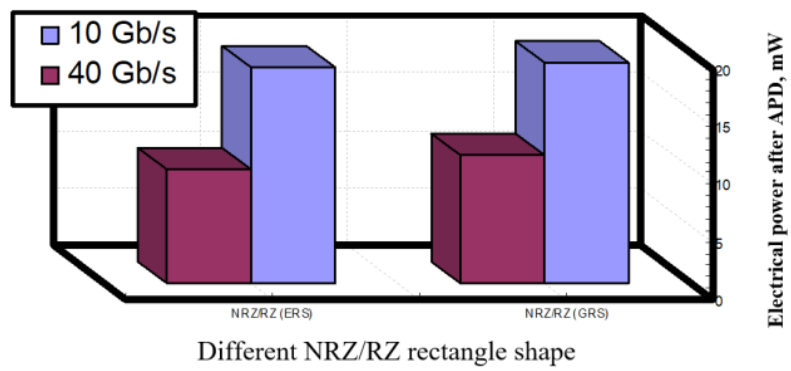

Figure 4. Electrical power after APD with overall system bit-rate based on different NRZ/RZ rectangle shape 


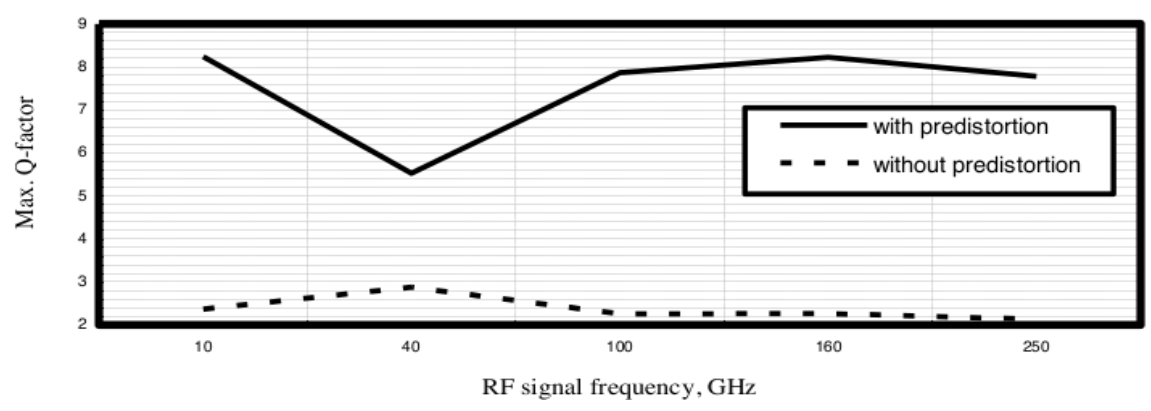

Figure 5. Max. Q-factor versus RF signal frequency in the presence and absence of the predistortion technique

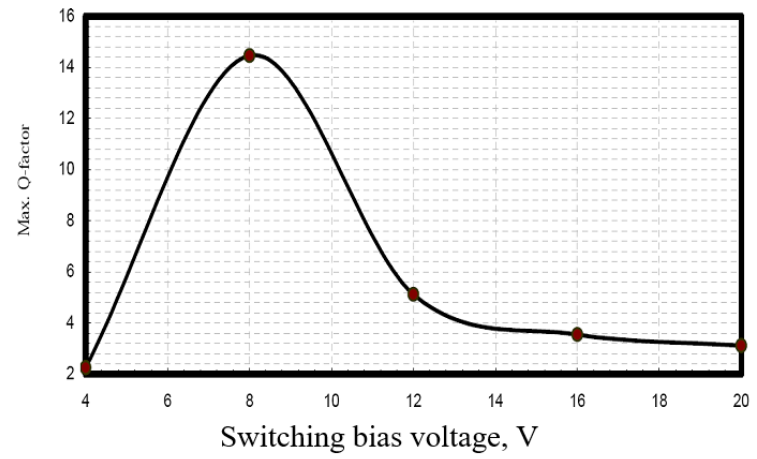

Figure. 6. Variations of max. Q-factor against variations of switching bias voltage based $\mathrm{LiNbO}_{3}$ Mach Zehnder Modulator at RF signal frequency of $100 \mathrm{GHz}$

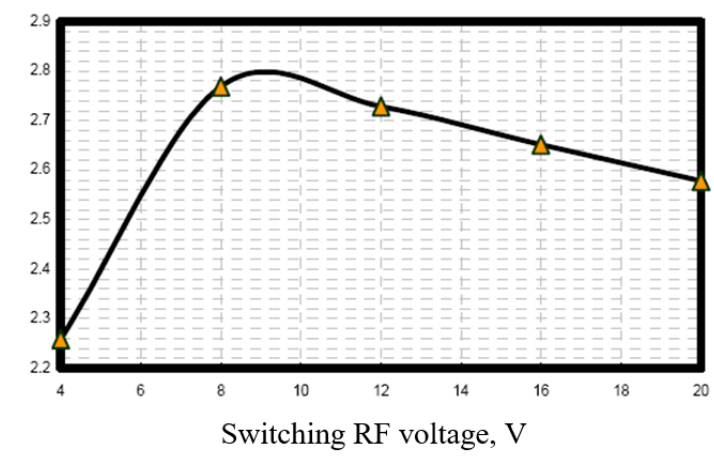

Figure. 7. Max. Q-factor with switching voltage based $\mathrm{LiNbO}_{3}$ Mach Zehnder Modulator at RF frequency of $100 \mathrm{GHz}$

Figures 8-11 indicate that the gain, noise figure, electrical power, and light signal/noise ratio with the switching bias voltage and switching RF voltage. The oscillation values between increasing and decreasing performance parameters under study. As shown in Figure 8, gain and noise figure are slightly decrease with the increase of the switching bias voltage. Also in the same way as clarified in Figure 9, gain and noise figure are slightly decrease with the increase of the switching RF voltage. As shown in Figure 10, electrical power and light signal to noise ratio are slightly decrease with the increase of the switching bias voltage. Also in the same way as clarified in Figure. 11, electrical power and light signal to noise ratio are slightly decrease with the increase of the switching RF voltage.

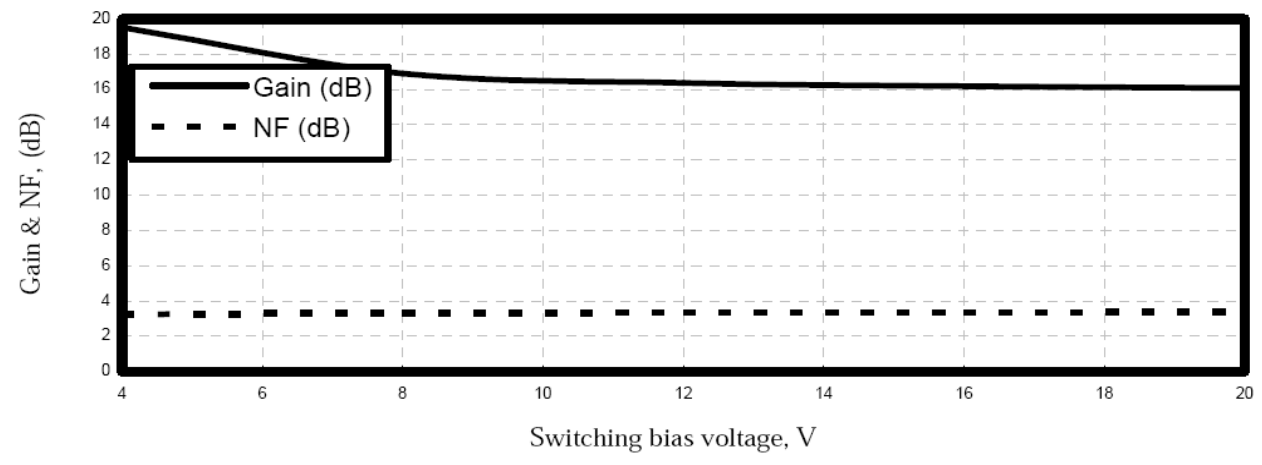

Figure 8. Gain, noise figure with switching bias voltage based $\mathrm{LiNbO}_{3}$ Mach Zehnder Modulator at frequency of $100 \mathrm{GHz}$ 


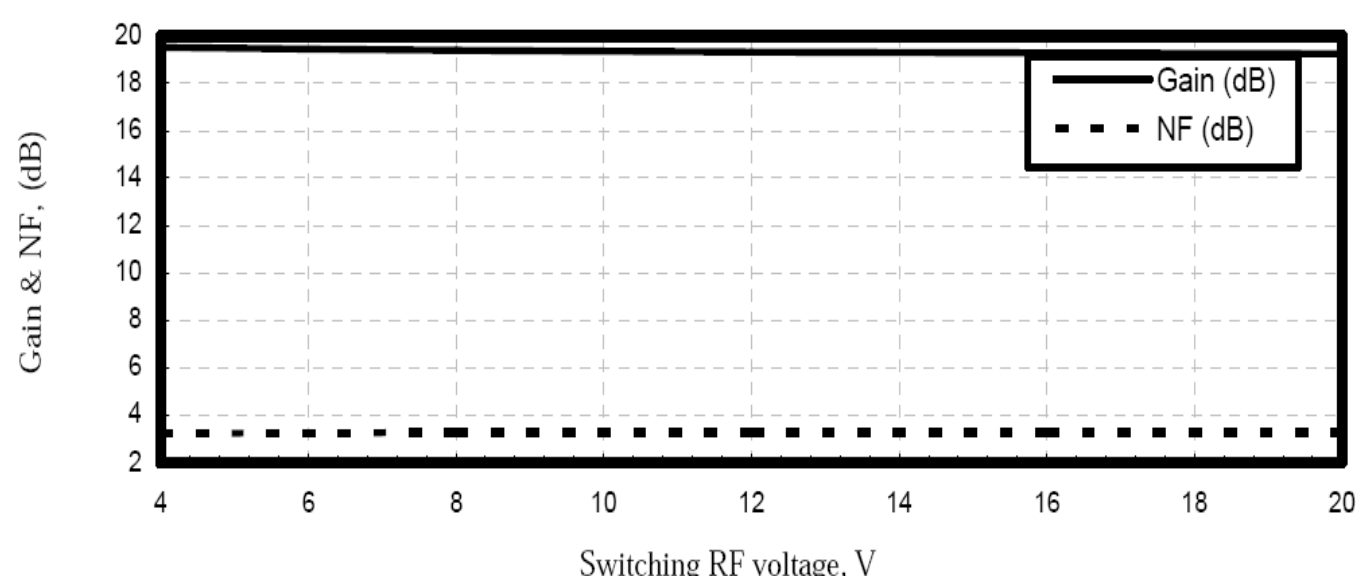

Figure 9. Gain, noise figure with switching RF voltage based $\mathrm{LiNbO}_{3}$ Mach Zehnder Modulator at frequency of $100 \mathrm{GHz}$

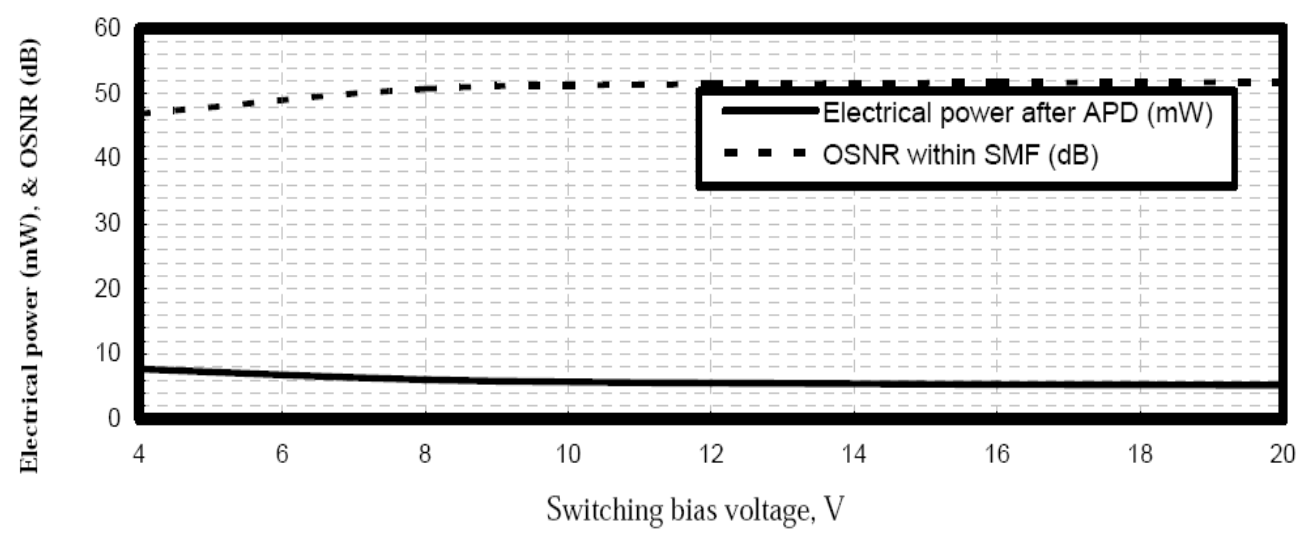

Figure 10. Variations of electrical power and light signal/noise ratio against variations of switching bias voltage based $\mathrm{LiNbO}_{3}$ Mach Zehnder Modulator at RF signal frequency of $100 \mathrm{GHz}$

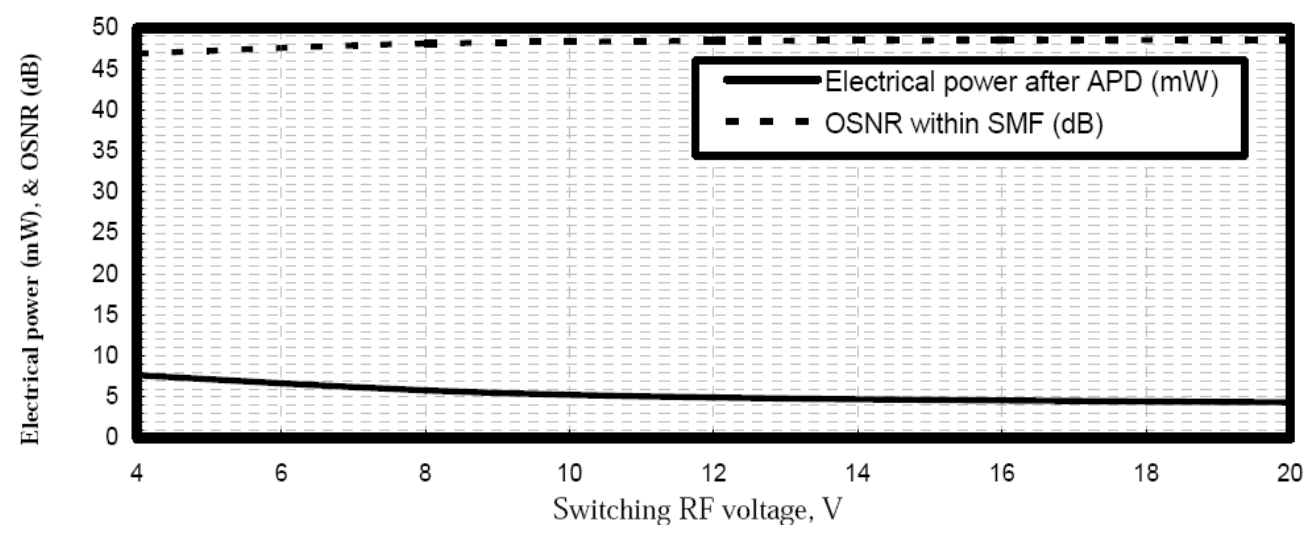

Figure 11. Electrical power and light signal/noise ratio versus switching RF voltage based $\mathrm{LiNbO}_{3} \mathrm{Mach}$ Zehnder Modulator at RF signal frequency of $100 \mathrm{GHz}$

Figures 12-15 show that eye diagram analyzer and BER analyzer for both NRZ/RZ (GRS) configuration, NRZ/RZ (ERS) configuration at different transmission bit rates. These graphs show the max Q-factor and min BER values exactly. The max. Q factor is 8.12 , min. BER is $2.2 \times 10^{-16}$ for NRZ/RZ (exponential rectangle shape) at $10 \mathrm{~Gb} / \mathrm{s}$ as clarified in Figure 12. The max. Q factor is 5.53, min. BER is 
$1.504 \times 10^{-8}$ for NRZ/RZ (exponential rectangle shape) at $40 \mathrm{~Gb} / \mathrm{s}$ as clarified in Figure 13 . The max. Q factor is 7.97 , min. BER is $7.64 \times 10^{-16}$ for NRZ/RZ (Gaussian rectangle shape) at $10 \mathrm{~Gb} / \mathrm{s}$ as clarified in Figure 14. The max. Q factor is 5.92, min. BER is $1.445 \times 10^{-9}$ for NRZ/RZ (Gaussian rectangle shape) at 40 $\mathrm{Gb} / \mathrm{s}$ as clarified in Figure 15. Figures 16, and 17 demonstrate that the variations of maximum modulated power after $\mathrm{LiNbO}_{3}$ Mach Zehender modulator without/with predistortion technique at $40 \mathrm{~Gb} / \mathrm{s}$. The enhancement of modulated signal peak power after predistortion technique. The max. signal power is 1.312 $\mathrm{dBm}$, noise power is $-104.824 \mathrm{dBm}$ without predistortion technique at $40 \mathrm{~Gb} / \mathrm{s}$ as clarified in Figure 16 . The max. signal power is $1.15548 \mathrm{dBm}$, noise power is $-104.824 \mathrm{dBm}$ with predistortion technique at $40 \mathrm{~Gb} / \mathrm{s}$ as clarified in Figure 17.

Figure 18 shows that Q-factor enhancement ratio, electrical power enhancement ratio and BER reduction ratio in relation to RF signal frequency. The Q-factor enhancement ratio, BER reduction ratio is achieved at $250 \mathrm{GHz}$, while the electrical power enhancement ratio is achieved at $160 \mathrm{GHz}$. The Q-factor enhancement ratio is $71.26 \%$ at $10 \mathrm{GHz}, 47.90 \%$ at $40 \mathrm{GHz}, 71.28 \%$ at $100 \mathrm{GHz}, 72.43 \%$ at $160 \mathrm{GHz}$, $72.69 \%$ at $250 \mathrm{GHz}$. Besides, the BER reduction ratio is $28.74 \%$ at $10 \mathrm{GHz}, 52.10 \%$ at $40 \mathrm{GHz}, 28.72 \%$ at $100 \mathrm{GHz}, 27.57 \%$ at $160 \mathrm{GHz}, 27.31 \%$ at $250 \mathrm{GHz}$. Moreover, the electrical power enhancement ratio is $2.2 \%$ at $10 \mathrm{GHz}, 8.10 \%$ at $40 \mathrm{GHz}, 58.41 \%$ at $100 \mathrm{GHz}, 65.60 \%$ at $160 \mathrm{GHz}$, and $60.88 \%$ at $250 \mathrm{GHz}$.

The complete comparison between maximum Q-factor, minimum BER, and electrical power after APD photodiode in the presence and absence of predistortion technique is summarized in Table 1 at different RF signal frequencies. As well as the performance parameters enhancement ratio are summarized in Table 2 at different RF signal frequencies.
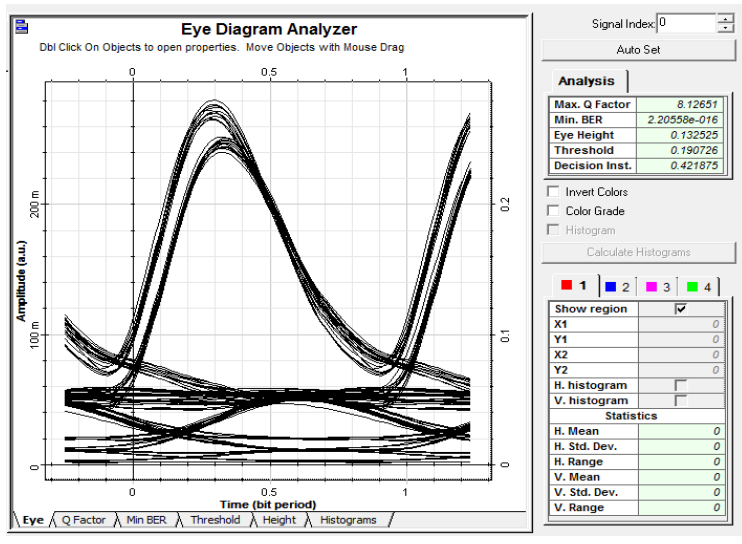

Figure 12. Eye diagram analyzer for NRZ/RZ (exponential rectangle shape) at $10 \mathrm{~Gb} / \mathrm{s}$
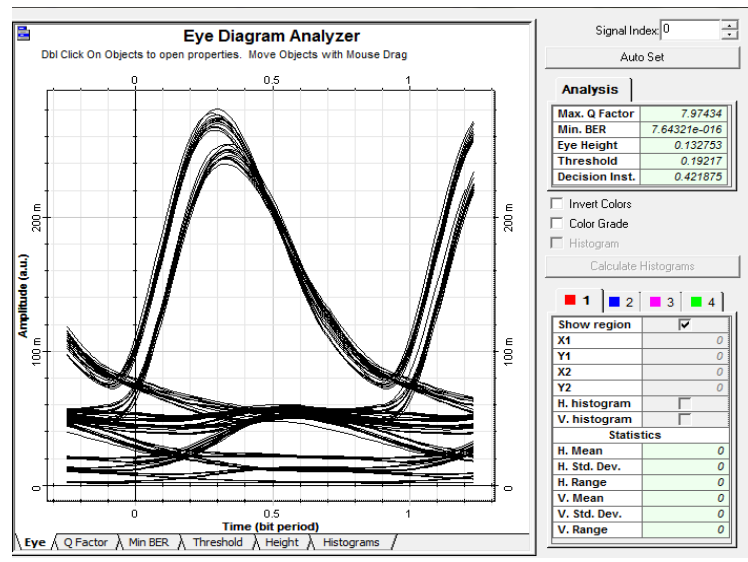

Figure 14. Eye diagram analyzer for NRZ/RZ (Gaussian rectangle shape) at $10 \mathrm{~Gb} / \mathrm{s}$

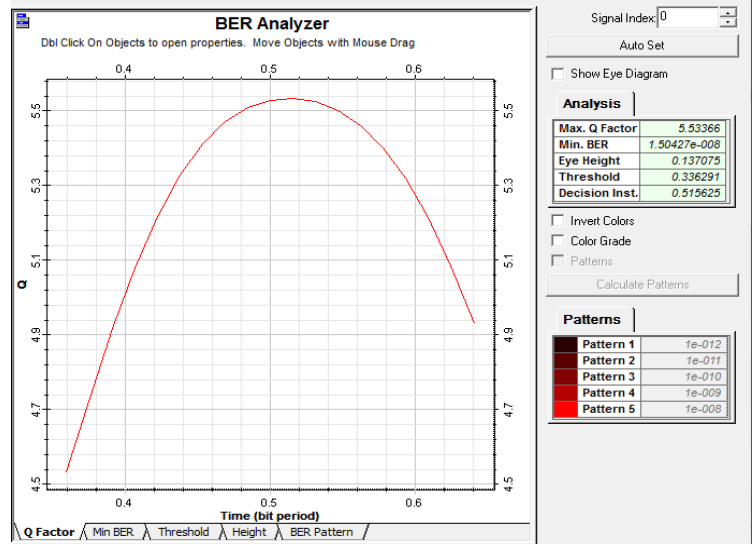

Figure 13. Bit error rate analyzer for NRZ/RZ (exponential rectangle shape) at $40 \mathrm{~Gb} / \mathrm{s}$

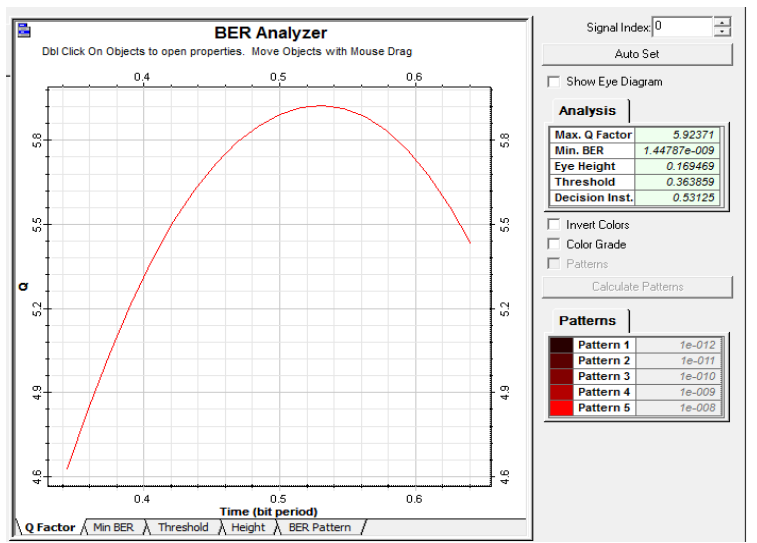

Figure 15. Eye diagram analyzer for NRZ/RZ (Gaussian rectangle shape) at $40 \mathrm{~Gb} / \mathrm{s}$ 

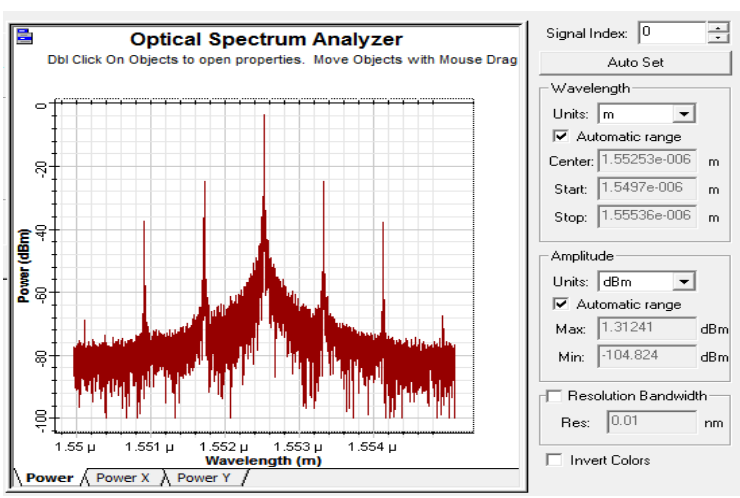

Figure 16. Max modulated power after $\mathrm{LiNbO}_{3}$ MZM without predistortion technique at $40 \mathrm{~Gb} / \mathrm{s}$
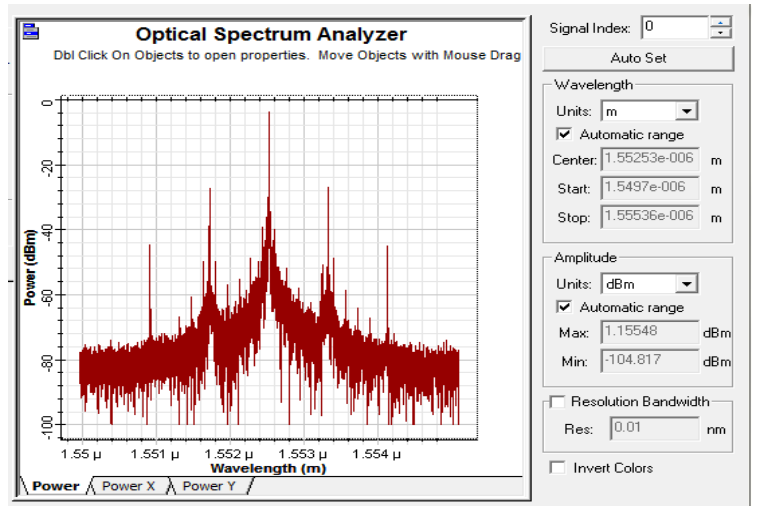

Figure 17. Maximum modulated power after $\mathrm{LiNbO}_{3}$ Mach Zehender modulator in the presence of predistortion technique at $40 \mathrm{~Gb} / \mathrm{s}$

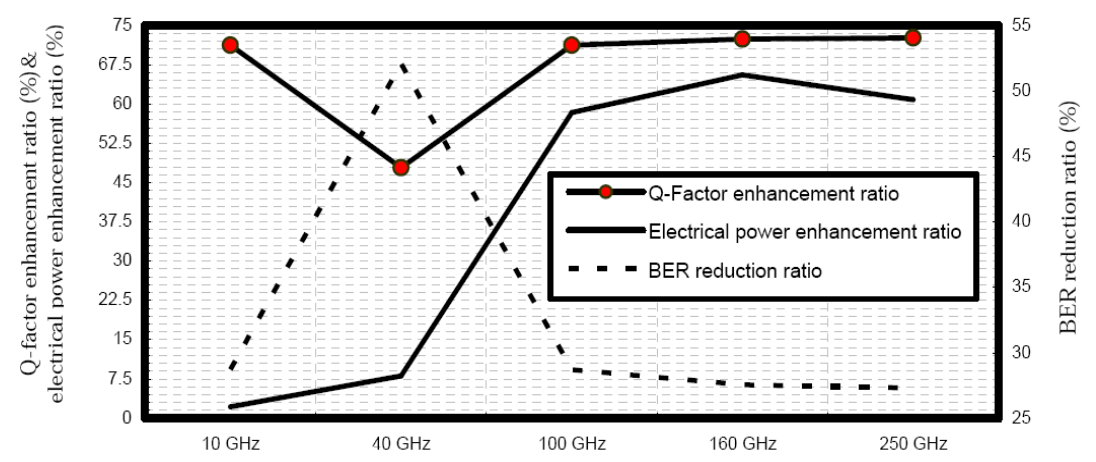

Figure 18. Q-factor enhancement ratio, electrical power enhancement ratio and BER reduction ratio in relation to RF signal frequency

Table 1. System performance parameters with/without predistortion technique

\begin{tabular}{|c|c|c|c|c|c|c|}
\hline \multirow{2}{*}{$\begin{array}{l}\text { RF signal } \\
\text { frequency }\end{array}$} & \multicolumn{3}{|c|}{ Without Predistortion technique } & \multicolumn{3}{|c|}{ With Predistortion technique } \\
\hline & $\begin{array}{l}\text { Max. Q- } \\
\text { factor }\end{array}$ & Min. BER & $\begin{array}{l}\text { Electrical power } \\
\text { after receiver }(\mathrm{mW})\end{array}$ & Max. Q-factor & Min. BER & $\begin{array}{l}\text { Electrical power } \\
\text { after receiver } \\
(\mathrm{mW})\end{array}$ \\
\hline $10 \mathrm{GHz}$ & 2.367 & 0.00889 & 13.016 & 8.238 & $8.71 \times 10^{-17}$ & 13.31 \\
\hline $40 \mathrm{GHz}$ & 2.881 & 0.0018844 & 9.098 & 5.53 & $1.5 \times 10^{-8}$ & 9.9 \\
\hline $100 \mathrm{GHz}$ & 2.258 & 0.0118947 & 7.682 & 7.864 & $1.673 \times 10^{-15}$ & 18.472 \\
\hline $160 \mathrm{GHz}$ & 2.267 & 0.011156 & 6.34 & 8.223 & $9.07 \times 10^{-17}$ & 18.432 \\
\hline $250 \mathrm{GHz}$ & 2.128 & 0.0164218 & 7.324 & 7.794 & $2.9 \times 10^{-15}$ & 18.725 \\
\hline
\end{tabular}

Table 2. System performance parameters enhancement ratio with predistortion technique

\begin{tabular}{cccc}
\hline RF signal frequency & Q-factor enhancement ratio (\%) & BER reduction ratio (\%) & Electrical power enhancement ratio (\%) \\
\hline $10 \mathrm{GHz}$ & 71.26 & 28.74 & 2.20 \\
$40 \mathrm{GHz}$ & 47.90 & 52.10 & 8.10 \\
$100 \mathrm{GHz}$ & 71.28 & 28.72 & 58.41 \\
$160 \mathrm{GHz}$ & 72.43 & 27.57 & 65.60 \\
$250 \mathrm{GHz}$ & 72.69 & 27.31 & 60.88 \\
\hline
\end{tabular}

\section{CONCLUSION}

In summary, we have simulated the radio over fiber communication based local area optical networks using duo-binary modulation and predistortion techniques. It is denied inferred that the enhancement of both signal quality and its power, in addition to the reduction in bit error rate in the presence of predistortion technique. It is observed that the NRZ/RZ in GRS configuration has presented max. Q-factor 
and min. BER at high data rates. It is efficient for electrical power saving. The optimum Q-factor is achieved at a value of 8 Volt for both switching bias voltage and switching RF voltage based Mach Zehnder modulator. In addition to the optical signal to noise ratio is slightly changed with the variations of both switching RF, switching bias voltages which belong to the modulator. It is indicated that the enhancement of modulated signal peak power to $1.15548 \mathrm{dBm}$ with predistortion technique, while its value is degraded to $1.31241 \mathrm{dBm}$ without predistortion technique. Finally, it is inferred that the maximum Q-factor enhancement ratio is reached to $72.69 \%$, the minimum BER reduction ratio is reached to 27.31 at $250 \mathrm{GHz}$, while maximum electrical power enhancement ratio is reached to $65.60 \%$ at $160 \mathrm{GHz}$.

\section{REFERENCES}

[1] Y. Okamura, and S. Yamamato, "Ultra-Low Loss Single Mode Fiber Design for 2.5-6 $\square \mathrm{m}$ Band Absorption," Applied Optics, vol. 22, no. 19, pp. 3098-3101, 1983S.

[2] S. S. Kumar, P. Keerthana, "Simulation of RoF using wavelength selective OADM," International Journal of Research Studies in Science, Engineering and Technology, vol. 2, no. 9, pp. 16-22, 2015.

[3] N. Singh, H. Kaur, "Amplitude noise reduction in millimeter wave radio-over-fiber systems by using filtration techniques," International Journal of Advanced Research in Computer and Communication Engineering, vol. 5, no. 7, pp. 302-306, 2016.

[4] K. Shrimali, A. Patel, "Performance analysis of ROF system using NRZ coding," International Research Journal of Engineering and Technology (IRJET), vol. 4, no. 1, pp. 1568-1570, 2017.

[5] A. A. Khadir, et al., "Achieving optical fiber communication experiments by optisystem," International Journal of Computer Science and Mobile Computing, vol. 3, no. 6, pp. 42-53, 2014.

[6] H. Tokiwa, and Y. Mimura, "Ultra-low Loss Fluorida Glass Single Mode Fiber Design", J. Lightwave Technol., vol. LT-4, pp. 1260-1266, 1986.

[7] A. Gupta, "Comparative analysis of various wavelength division multiplexed PON standards," Journal of Optical Communications, vol. 40, no. 1, pp. 51-54, 2019.

[8] A. Sheetal, H. Singh, "Cost Efficient $4 \times 2.5 \mathrm{~Gb} / \mathrm{s}$ Transparent WDM Ring network using DML and metro cor fiber for long reach applications," Journal of Optical Communications, vol. 40, no. 1, pp. 67-74, 2019.

[9] S. Iyer, S. P. Singh, "Effect of channel spacing on the design of mixed line rate optical wavelength division multiplexed networks," Journal of Optical Communications, vol. 40, no. 1, pp. 75-82, 2019.

[10] S. Driz, A. Djebbari, "Performance evaluation of sub-carrier multiplexed SAC-OCDMA system using optimal modulation index," Journal of Optical Communications, vol. 40, no. 1, pp. 83-92, 2019.

[11] F. M. Ghannouchi, O. Hammi, "Behavioral modeling and predistortion," IEEE Microwave Magazine, vol. 10, no. 7, pp. 52-64, 2010.

[12] F. Vendittia et al., "Fluorides decontamination by means of Aluminum polychloride based commercial coagulant ", J. of Water Process Engineering, Vol. 26, pp. 182-186, 2018.D. Gustafsson, et al., “A wideband and compact GaN MMIC dohertyamplifier for microwave link applications," IEEE Transactions on Microwave Theory and Techniques, vol. 61, no. 2, pp. 922-930, 2013.

[13] W. J. Tomlinson and R. H. Stolen, "Nonlinear Phenomena in Optical Fibers", IEEE Comm. Magazine, Vol. 26, No. 4, pp. $36-44,1988$

[14] S. Mitachi and T. Miyashita, "Refractive Index Dispersion for BaF2-GdF3-ZrF4-AlF3 Glasses", Applied Optics, vol. 22 , no. 16 , pp. 2419-2425, 1983.

[15] S. M. Nagia et al., "Fluoride release and recharge of enhanced resin modified glass monomer at different time intervals," Future Dental Journal, vol. 4, no. 2, pp. 221-222, 2018.

[16] A. Zhu, et al., "Digital predistortion for envelope-tracking power amplifiers using decomposed piecewise Volterra series," IEEE Trans. Microw. Theory Tech., vol. 56, no. 10, pp. 2237-2247, 2008.

[17] S. S. Walker, "Rapid Modelling and Estimation of Total Spectral Loss in Optical Fibers," J. Lightwave Technol., vol. LT-4, no. 8, pp. 1125-1137, 1986.

[18] H. E. H. Ahmed et al., "On the Propagation Characteristics of Fluoride and Germania Doped Optical Fibers", Ain Shams Univ. Eng. Bulletin, vol. 27, no. 4, pp. 241-255 1992.

[19] K. Kitayama et al., "Design Considerations for the Structural Optimization of a Single Mode Fiber", J. Lightwave Technol., vol. LT-1, no. 2, pp. 363-369, 1983.

[20] D. Wood, "Constraints on the Bit Rates in Direct Detection Optical Communication Systems Using Linear or Soliton Pulses:," J. Lightwave Technol., vol. 8, no. 7, pp. 1097-1106, 1990.

[21] R. Sanjari and M. Pourmahyabadi, "Design of Single Mode Photonic Crystal Fiber with Outstanding Characteristics of Confinement Loss and Chromatic Dispersion over S and L Communication Band", Iranian Journal of Electrical \& Electronic Engineering, vol. 12, no. 1, pp. 29-34, 2016.

[22] F. Öhman, et al., "Noise and regeneration in semiconductor waveguides with saturable gain and absorption," IEEE J. Quantum Electron., vol. 40, no. 3, pp. 245-255, 2004.

[23] S. Iyer, S. P. Singh, "Effect of Channel Spacing on the Design of Mixed Line Rate Optical Wavelength Division Multiplexed Networks," Journal of Optical Communications, vol. 40, no. 1, pp. 75-82, 2019.

[24] V. R. Miriampally, T. Hailu, "2D Single Mode Optical Fiber Wave Guide Design for Multi Haul Applications," International Journal of Innovative Research in Electronics and Communications (IJIREC), vol. 3, no. 5, pp. 2435, 2016, DOI: http://dx.doi.org/10.20431/2349-4050.0305004, www.arcjournals.org. 
[25] F. E. Seraji, R. Kiaee, "A Revisit of Refractive Index Profiles Design for Reduction of Positive Dispersion, Splice Loss, and Enhancement of Negative Dispersion in Optical Transmission Lines," International Journal of Optics and Applications, vol. 4, no. 2, pp. 62-67, 2014, DOI: 10.5923/j.optics.20140402.06.

[26] S. A. Bhuiyan, "Design, Simulation, Performance Analysis and Optimization Process of MMGRIN Fiber with RI Distribution," 1st International conference on Electrical \& Communication Engineering and Renewable Energy, pp. 1-6, 2014.

[27] M. Artiglia, "Mode field Diameter Measurements in Single Mode Optical Fibers," Journal of Lightwave Tech., vol. 7, no. 8, pp. 11391152, 1989.

[28] V. Palodiya, S. K. Raghuwanshi, "Dispersion Characteristics of Novel Class Multi Clad Dispersion Shifted Hollow Core Fibers for WDM Optical Systems," Indian Journal of Pure \& Applied Physics, vol. 56, pp. 76-79, 2018.

[29] Hazem M. El-Hageen, et al., "RZ line coding scheme with direct laser modulation for upgrading optical transmission systems," Open Eng. Journal, vol. 10, no. 1, pp. 546-551, 2020. https://doi.org/10.1515/eng-20200066.

[30] Ahmed Nabih Zaki Rashed, et al., "High-speed signal processing and wide band optical semiconductor amplifier in the optical communication systems," Journal of Optical Communications, Published Online: 25 July 2020. https://doi.org/10.1515/joc-2020-0070.

[31] C. Kromer et al., "A Low-Power 20-GHz 52-dB Transimpedance Amplifier in 80-nm CMOS," IEEE Journal of Solid State Circuits, vol. 39, no. 6, pp. 885-894, 2004.

[32] D. Praveen, et al., "A Comparative Analysis of Transimpedance Amplifier in Giga-bit Optical Communication," Research Journal of Engineering Sciences, vol. 3, no. 3, pp. 6-9, 2014.

[33] Lucas M. Riob, et al., "Wideband Transimpedance Amplifiers for Optoelectronics: Applications to Dynamic Interferometry," Revista elektron, vol. 1, no. 1, pp. 16-22, 2017.

[34] L. Safar, M. S. Zaki, "Design and Simulation of Differential Transimpedance Amplifier (TIA) Based on $0.18 \mu \mathrm{m}$ CMOS Technology," Al-Rafidain Engineering, vol. 21, no. 4, pp. 121-130, 2013.

[35] X. Hui, et al., "A 3.125-Gb/s Inductor Less Transimpedance Amplifier for Optical Communication in $0.35 \mu \mathrm{m}$ CMOS," Journal of Semiconductors, vol. 32, no. 10, pp. 105003 (1-6), 2011.

[36] S. Subi, and G. b. Lakshmi, "Optical Solitons Simulation Using DSF and Optical Pulse Generator in Single Mode Optical Fiber," International Journal of Science and Research (IJSR), ISSN (Online): 2319-7064, vol. 4, no. 2, pp. 254-258, 2015.

[37] M. Arora and G. Pandove, "Simulated Circuit for Generation of $40 \mathrm{GHz}$ Soliton Train," International Journal of Emerging Trends in Electrical and Electronics (IJETEE - ISSN: 2320-9569), vol. 5, no. 2, pp. 73-76, 2013. 